\title{
ENHANCEMENT OF SOLUBLE PHOSPHATE IN THE SOIL PROFILE BY EARTHWORMS.
}

\author{
M.C.H. MOUAT and R.G. KEOGH \\ Grasslands Division, \\ DSIR, Palmerston North.
}

A bstract

Soil from subsurface wormcasts and from the lining of earthworm burrows had more water soluble phosphate than the surrounding soil at all soil depths sampled down to $250 \mathrm{~mm}$. The absolute effect of earthworm presence on water soluble phosphate concentration decreased markedly with depth.

While earthworms increase soluble phosphate concentration down the soil profile, the availability of the redistributed phosphate is somewhat attenuated with depth, probably through its being resited in soil of greater phosphate absorbing power than that of the surface K eywords: Earthworms, available phosphate, phosphate distribution

\section{INTRODUCTION}

Wormcasts, the faecal deposits of earthworms, are high in water-soluble phosphate (Sharpley and Syers 1976) and their presence increases the available phosphate in soil (Mackay et al. 1983) and uptake of phosphate by pasture plants (Mansell et al. 1981). Not all earthworm faeces are deposited as casts on the soil surface. Darwin (1981) observed that earthworm burrows were lined with a thin layer of fine dark coloured earth voided by the worms, and that the walls of fresh burrows were often dotted with little globular pellets of voided material. Bouche (1981) and co-workers (Bouche et al. 1983) have deduced that $70 \%$ of the faeces of burrow- and cast-forming earthworms are deposited in subsurface horizons of the soil.

The concentration of water-soluble phospate has been shown to be the critical factor for pasture growth under conditions of phosphate limitation (Ozanne and Shaw 1967), and this concentration declines rapidly with soil depth in pasture soil (Jackman and Mouat 1972). It is possible that subsurface faecal deposition could provide pockets of high phosphate concentration down the soil profile producing regions favouring uptake by clover relative to grass (Jackman and Mouat 1972).

\section{METHODS}

Soil blocks approximately $200 \mathrm{~mm}$ square and $300 \mathrm{~mm}$ deep were taken from a pasture on Tokomaru silt loam (Cowie 1978) in February in the middle of a dry summer. The pasture soil contained a lumbricid earthworm population of Allolobophora caliginosa (Sav.). A. longa (Ude) and Lumbricus rubellus (Hoff.). The blocks were dissected and soil samples taken from the linings of burrows and chambers constructed by earthworms. A $1.2 \mathrm{~mm}$ thick layer of the lining of burrows and chambers was removed by scraping. Another sample of soil just beyond this lining layer was taken (designated "near" sample) and further samples were taken of soil apparently not recently in close contact with earthworms. Also, some obvious casts were found in subsurface chambers and these were sampled as were casts found above the soil surface. The depth from the soil surface of all samples was recorded.

Subsamples of $0.1 \mathrm{~g}$ air dry soil were equilibrated with $4 \mathrm{ml}$ of $0.001 \mathrm{M} \mathrm{CaCl} 1_{2}$ with intermittent shaking for three days in the dark at $25^{\circ} \mathrm{C}$. Supernatant solutions were solutions were filtered $(0.45 \mu \mathrm{m})$ and analysed for phosphate by the method of Murphy and Riley (1962). 


\section{RESULTS}

Phosphate concentration fell away sharply with increase in depth of the soil. The equilibrium water-soluble phosphate concentrations of soil from burrow linings were greater than those from undisturbed soil at similar depths while those of soils near to the burrow lining were intermediate between the two (Fig. 1). Exponentials were fitted to the three sets of samples and the lines fitted showed a significant increase $(p<0.001)$ in phosphate concentration in the burrow lining over that of the proximate and distant soil samples. No such relationship was found for the seven subsurface casts sampled, but their phosphate equilibrium concentrations were all very much lower than those of casts sampled above the soil surface $(77 \mu \mathrm{mol})$.

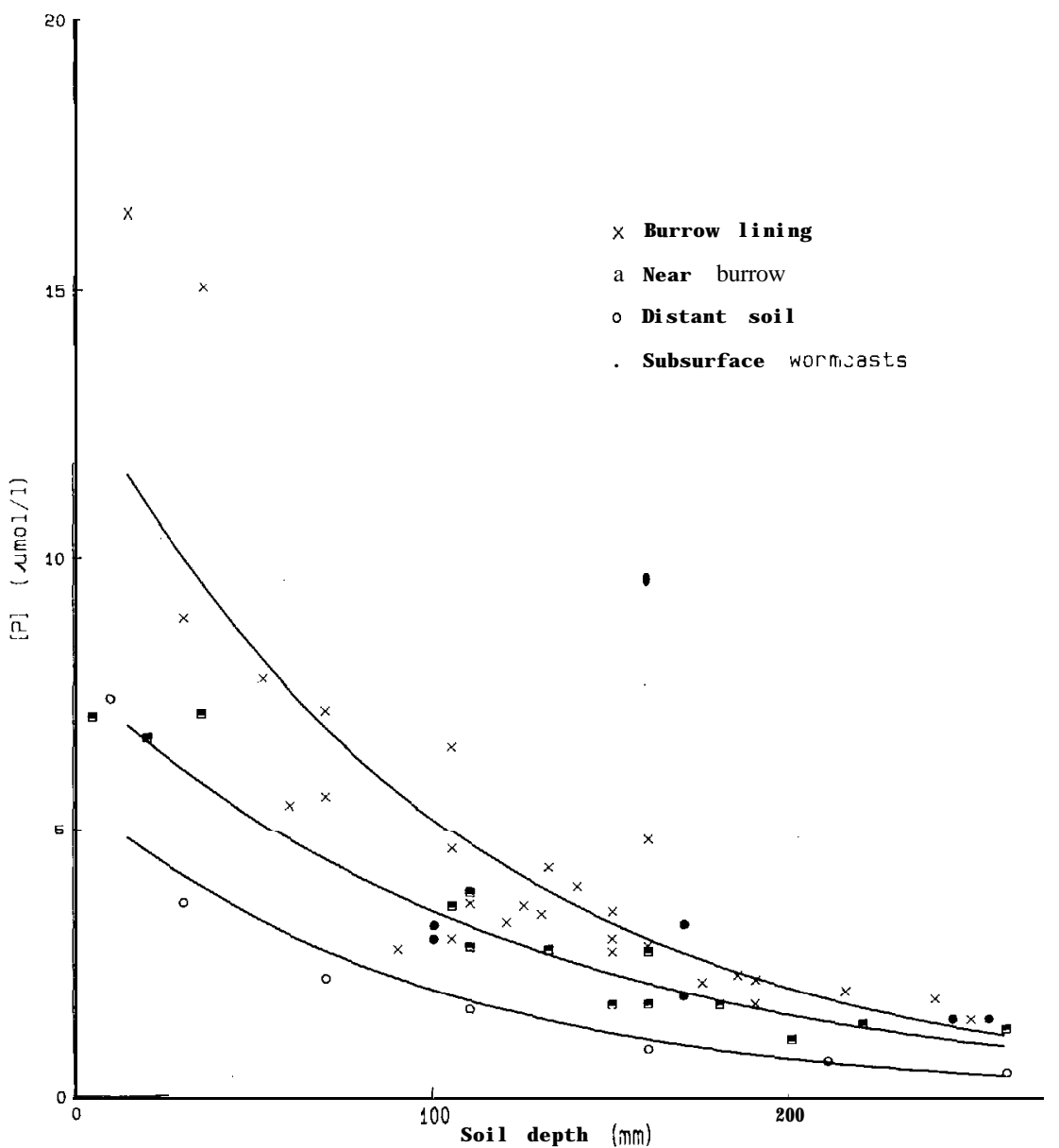

FIGURE 1: Effect of Presence of Earthworms on Concentration of Phosphate in Equilibrium Solution, [Pi . Data From Soil Not Affected By Earthworms (Distant Soil) Are M eans of 7 Replicates.

Lines shown are of form $[P]=a e^{-\mathbf{b} . \text { Depth. }}$

In [P] Distant soil + 1.720 .0102 Depth, $r+.97^{\star * *}$

In $[\boldsymbol{P}]$ Near burrow + 2.06. 0.0081 Depth, $r+-.95^{* * *}$

In [P] Burrow lining +2.590 .0094 Depth, $r+.87^{\star \star \star}$ 


\section{DISCUSSION}

Under conditions of low phosphate supply, the rate of uptake of phosphate by pasture plants is limited by the concentration of phosphate in solution. Ozanne and Shaw (1967) found that response to phosphate indicative of phosphate limitation to plant growth, could be expected if the phosphate concentration in solution in equilibrium with the soil was below $10 \mu \mathrm{M}$. The soil of the present study had been well fertilised for many years with superphosphate and the upper soil had a concentration of about $7.5 \mu \mathrm{M}$ P. This is a higher soluble phosphate level than most New Zealand pasture soils. The equilibrium phosphate concentrations found in the surface casts were over $70 \mu \mathrm{MP}$ or $2.8 \mu \mathrm{mol}$ water-soluble $\mathrm{P} / \mathrm{g}$ of casts. This is similar to the $1 \mu \mathrm{mol}$ water-soluble P/g found by Sharpley and Syers (1976).

The large amount of wormcasts, high in soluble phosphate, deposited on the soil surface has been considered to make a major contribution to the phosphate nutrition of pastures (Hay 1983). An even larger amount of earth faeces deposited below the soil surface (Bouche 1981, Bouche et al. 1983) would therefore be expected to enhance the soluble P status of the P-deficient sub-surface horizons. Sharpley and Syers (1977) stated that the gain in total P in wormcasts over that of underlying soil was mostly in water-soluble P. If the annual deposition of surface casts is 25 (Sharpley and Syers 1977) to 42 (Bouche 1981) t/ha containing the content of water-soluble phosphate sampled here $(2.8 \mu \mathrm{mol} / \mathrm{g})$ and the ratio of surface casts to that deposited in subsurface horizons is $30: 70$ (Bouche et al. 1983), then 5.1 to $8.5 \mathrm{~kg}$ water-soluble $\mathrm{P}$ (the equivalent of 60 to $100 \mathrm{~kg}$ of superphosphate) per hectare will be deposited annually by earthworms below ground. However, the faecal deposits sampled from the burrow linings did not show the same high concentration of phosphate as did the surface casts and the further from the surface that the sample was taken, the less was the increase in soluble phosphate over that of soil distant from the burrow.

This fall-off in increase in phosphate concentration with depth is illustrated in Fig. 2. Many factors could be involved in this reduction. Autocoprophagy is important in earthworm nutrition (Bouche et al. 1983) and an attendant loss in soluble phosphate could result and give an unequal distribution in the profile. A more certain reason for the decrease will be the increase in phosphate adsorption by the soil with increase in depth. This is indicated by thdreduction in equilibrium solution-phosphate with depth in the undisturbed (distant) soil in the present trial and in profile analyses of earlier trials (Jackman and Mouat 1972). Increase in phosphate retention with depth has been shown on the same soil type as studied in this trial (Mackay et al. 1983). More retentive soil could reduce phosphate concentration through soil contamination in the burrow lining sample or through diffusion of the soluble phosphate to adsorption sites of the soil before sampling. The latter case is the more probable reason since the effect of soil depth is less obvious in the increase in phosphate concentration of the "near" burrow samples (Fig. 2) and the subsurface casts, which exhibited a phosphate concentration well below the $70 \mu \mathrm{M}$ of surface casts, were removed undisturbed from their chambers and had no soil contamination although they would have had contact through solution with the surrounding soil.

It would appear, therefore, that while increasing the range of soluble phosphate down the soil profile, the availability of the redistributed phosphate is reduced by its being resited in soil of greater phosphate-adsorbing power than that of the surface.

Despite this limitation, the increased phosphate availability down the profile may result in significantly better phosphate nutrition and growth of white clover relative to grass. Results of Ozanne and Shaw (1967) indicate that as the solution equilibrium phosphate concentration falls below $4 \mu M$, there is a rapid decline in pasture yield. From Fig. 1, it can be seen that earthworm presence can raise the phosphate concentration from a value very much less than $4 \mu M$ to above that critical level at depths between 40 and $150 \mathrm{~mm}$. It is in this range of soil depths that clover appears to 


\section{Upper line; from distant soi I to burrow Ii ni ng}

Lower Iine; from distant soi I to near burrow

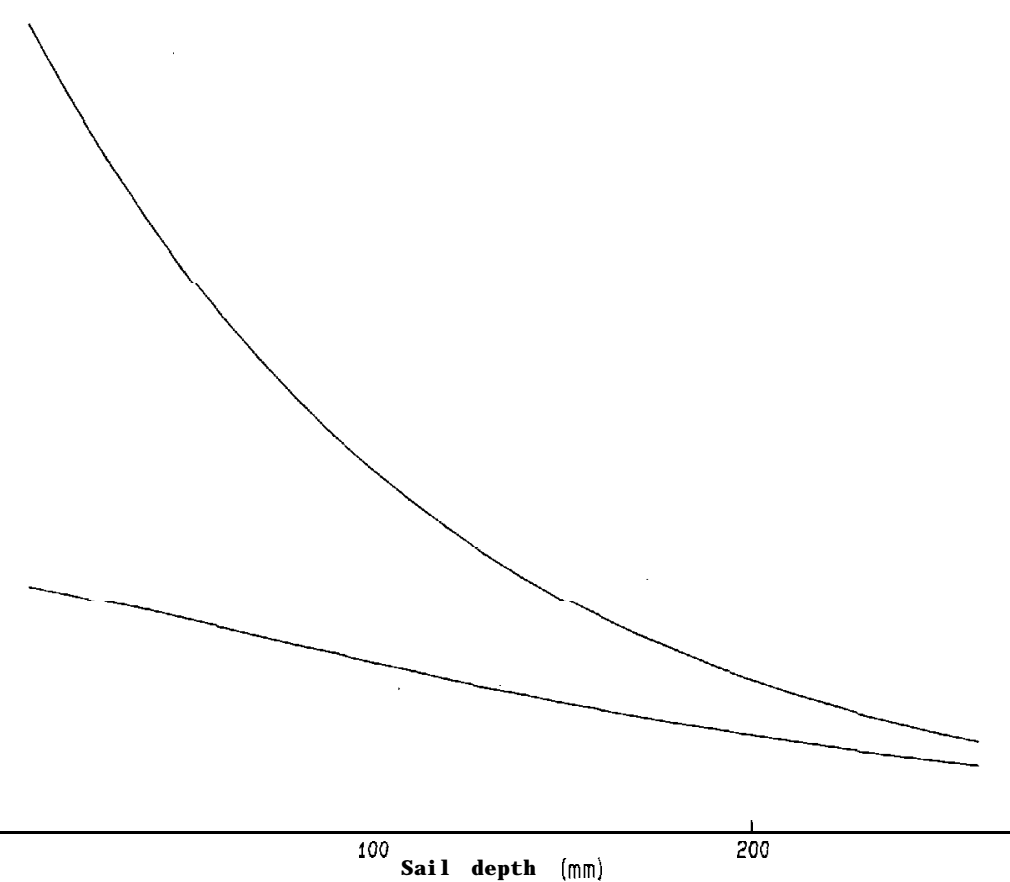

FIGURE 2: Effect of Depth of Soil Profile on the Absolute Increase in Phosphate Concentration, [F] $]$, Through Proximity of Earthworm Burrows.

have its maximum competitive advantage in the uptake activity of its roots. At these depths $(40-150 \mathrm{~mm})$, the relative root activity of white clover has been shown to be twice that of associated browntop (Jackman and Mouat 1972), and competition for phosphate from associated grass is a major limitation to clover growth under conditions of phosphate shortage. Increase in the numbers and activity of the burrow forming (e.g. A. longa) component of the earthworm population could thereby result in better phosphate nutrition of white clover and hence, better pasture production.

\section{References}

Bouche, M.B. 1981. CR. Coll. Int. CNRS Nancy No. 303: 145-153.

Bouche, M.B.; Radifison, Z.; Toutain, F. 1983 Rev. Ecol. Biol. Sol 20: 49-75.

Cowie, J.D. 1978 N.Z. Soil Bur. Bull. 33: 92pp.

Darwin, C. 1881 The formation of vegetable mould through the action of worms with observations on their habits. John Murray, London 326pp.

Hay, M.J.M. 1983 N.Z. J. agric. Res. 26: 29-34

Jackman, R.H.; Mouat, M.C.H. 1972 Ibid 15: 667-675.

Mackay, A.D.; Springett, J.A.; Syers, J.K.; Gregg, P.E H. 1983 Soil Biol, Biochem. 1.5: 63.73. 
Mansell, G.P.; Syers, J.K.; Gregg, P.E.H. 1981 Ibid 13:163.167

Murphy, G. Riley, JP, 1962, Angl Chim Acta 27: 31-36. 16316

Ozanne, P.G.; Shaw, T.C. 1967 Aust. J. Agric. res. 18: 601-612

Sharpley, A.N.; Syers, J.K. 1976 Soil Biol Biochem. 8: 341-346.

Sharpley, A.N.; Syers, J.K. 1977 lbid 9: 227-231. 